\title{
From Usability to Marketing
}

\author{
Syed Asim Ali \\ Department of Computer \\ Science, University of \\ Karachi, Pakistan
}

\author{
Anum Yaqoob \\ Faculty of Computer \\ Science, IBA, Karachi, \\ Pakistan
}

\author{
Saima Suri \\ Faculty of Computer \\ Science, IBA, Karachi, \\ Pakistan
}

\author{
Farhan Ahmed \\ Siddiqui \\ Department of Computer \\ Science, University of \\ Karachi, Pakistan
}

\begin{abstract}
This paper defines the term usability and usability engineering which operates in a way such that it incorporates usability into a product from $A$ to $Z$. This basically in-builds usability in to the process of creating a product. The term usability engineering is self explanatory in a way that it talks in the paradigm of engineering. The later part of this paper discusses the significance of usability in a products lifecycle and how usability helps create a user experience that is then magnified by marketing to create a brand's perception. The connection between usability and marketing has now blurred lines to define new strategies that motivate new theories to create unique selling identities.
\end{abstract}

\section{Keywords}

Usability, marketing

\section{INTRODUCTION}

\subsection{USABILITY}

From the beginning, the field of HCI has mainly focused on the usability aspect of products or systems. Neilson has defined the usability of a computer system through five different attributes, namely, efficiency, learnability, memorability, errors and satisfaction.

According to International Standards Organization (ISO) usability is "...the effectiveness, efficiency and satisfaction with which specified users can achieve specified goals in particular environments."

Both of the above definitions take into account only the functional aspects of usability.

\section{USABILITY ENGINEERING}

Usability Engineering has historically been considered synonymous to Human Computer Interface, user interface and graphics but in actuality it is a much deeper concept as it refers to a complex set of choices that allow users to perform one or more complex task in a system more efficiently, effectively, enjoyably and with a minimum of errors.

This is a field of study that covers two major aspects, namely, 'usability' and 'engineering'. Therefore it is a part of a project or a products construction from its inception to its final stage where it is released into the market and even afterwards in the maintenance phase. Several major disciplines including psychology, human factors and cognitive science include usability engineering, but the theoretical foundations of the field come from more specific domains: human cognition; behavioral research methodologies; human perception and action; and, to a lesser extent, quantitative and statistical analysis approaches.

There are several definitions and descriptions of usability engineering. Hix \& Harrison (1993) defined usability engineering as 'a process through which usability characteristics are specified, quantitatively and early in the development process and measured throughout the process', whereas Sun Usability

Labs (2001) added the notion of getting feedback from users: 'usability engineering is an approach to product development that is based on customer data and feedback'. From another perspective Faulkner's idea of usability engineering focuses on participatory design, calling out to the importance of users involvement in product development, 'an approach to the development of software and systems which involves user participation from the outset and guarantees the efficacy of the product through the use of a usability specification and metrics.

One thing to keep in mind is that usability and usability engineering should be treated differently. Where usability can often be considered a design aspect to be implemented as a part of graphical user interface, usability engineering is something that should be an integral part of the construct and needs to be part of the overall project or product from the first day that the concept is thought. In essence usability engineering ensures that 'usability' is embedded and an ingrained part of a product or project and to make sure this happens UE in software engineering is not just a part of the design phase but the overall construction and deliverance of the product

\section{USABILITY AND PROFITABILITY}

In a paper by Patrick W. Jordan (1998) 'Human factors for pleasure in product use' he presents an interview-based study that looks the subject of 'pleasure' in product use. The study was a first at considering hedonic and experiential benefits and penalties related with product use, and at finding out the properties that influence how pleasurable or displeasurable a product is to use. The study found out that 'feelings' associated with using pleasurable products included security, confidence, pride, excitement and satisfaction. For displeasurable products, associated feelings were annoyance, anxiety, contempt and frustration. The properties of products that were significant in terms of influencing the level of pleasure/displeasure with a product included features, usability, aesthetics, performance and reliability. Responses to questions investigating behavioral correlates to pleasure in product use suggested that pleasurable products were used more regularly and that future purchase choices would be affected by the level of pleasure in product use. The paper concluded that the issue of pleasure in product use involves more than usability alone. As the user's representative in the product creation process, the human factors specialist should consider many other factors in order to ensure that the user's experience of product use is maximized. One important aspect of designing such products for users is to understand the user itself. 


\section{UNDERSTANDING THE USER}

One of the simplest ways of creating this understanding is through a simple user and task analysis. Then a function assignment is performed to identify the distribution of tasks between the user and the system. The outcome of this understanding gives a user's mental model, which is a representation of the problem the users faced while accomplishing their tasks. With a clear understanding of the mental models designers can easily create system models that supplement and support the users.

\section{USER ANALYSIS}

This portion basically defines the user in detail. It clearly defines who the intended users of the system are with the help of a series of context-free, open-ended questions regarding the users experience (what is the expertise of the user, novice or expert?, how comfortable they are with the use of IT?, how often do they perform certain tasks?), context (what the working environment is?, is work done in a group or alone?, who installs and maintains the system?, are any cultural or international issues present and need to be dealt with?) and expectations (how does the user like working with the product or the system?, what features is the user looking for?). With the answers of these questions valuable information about the users can be retrieved and this can really help in the overall comprehension of where the user is coming from, what they are looking for and what they require in the overall sense.

\section{TASK ANALYSIS}

Task Analysis basically seeks to answer two main questions:

How will the system augment, change, enhance, modify or replace tasks being performed by the users now? And What tasks will the users perform in the new system?

For this purpose task analysis is taken through four main steps.

\section{Identify the tasks}

\section{Locate individuals who perform these tasks}

\section{Interview and observe}

\section{Create an overall roadmap}

All of these steps can be followed by context-free questions which will help develop a clear understanding of how the system is currently being used, what changes need to be implemented and how the system can be altered to provide better usability in future. With all these steps an overall clear roadmap is created which help understand what kind of changed, altered or redesigned interaction does the user need in the future versions. In an overall sense this could very easily help the designer in determining whether to alter a product or just simply design a new one. On the whole this can help in the profitability by saving a lot of extra revenue cost spent on product development or renovation.

\section{AESTHETICS}

With the penetration of digital technology into our everyday lives, to the point that it has defined how we conduct our daily activities and the environment we live in, has led to a lot of research and study on how to design or engineer these digital products. Most of this research is about making digital artifacts effective, intuitive, easy and enjoyable to use, all in order to enable the user to efficiently complete their tasks. All of these aspects come under the scope of usability, previously the study of usability consisted of research that only looked at the functional aspects designing digital systems i.e. effectiveness, efficiency and user satisfaction. But with technology playing a key role in the everyday lives of a user, new elements that define Human Computer Interaction have come into play one of these important elements is 'aesthetics'.

Researchers have defined aesthetics in different ways and the term aesthetics has no single definition. Some researchers describe aesthetics as the user's response to the look and feel of a product. Other researchers differentiate aesthetics as either expressive or classical. Expressive aesthetics is characterized by original and creative design. Whereas, classical aesthetics represents a more traditional form of design with orderliness and clarity as important elements. This also includes the use of harmonious colors and symmetric patterns.

The study of aesthetics is not just limited to the design of interactive products but has also attracted attention of the product-design community and the field of human factors and ergonomics. This can be observed through the growing number of studies on the influence of aesthetics on the usability of a product or system. There are certain researchers who agree that aesthetics impacts the perceived usability of a system positively and that aesthetics also has a positive effect on performance. The positive affect of aesthetics on performance is mainly attributed to Normans 'positive affect' theory. The positive effect, as defined by psychology, helps the user in problem solving and so good aesthetics improves user performance by allowing the user to perform tasks quickly, here aesthetics even compensate for systems with average usability.

\section{FROM USABILITY TO MARKETING}

Often times a designer might consider himself the user but the fact is the demarkation is very specific. In very simple terms if we consider a designer of a word processor who, assuming himself to be the user, tests the word processor and gives it the go ahead might already have included his own biases on skill level into the user testing. For that designer would probably be very proficient with the system and would know all the ins-and-outs of the program whereas any new user might take some time to get acquainted with the system before he could even use it let alone become as proficient as the designer.

This is one aspect that needs to be very carefully monitored in usability also that the designers not consider themselves the user and instead of getting proper user-testing they just define a systems or products capabilities themselves. There are obviously other concerns, many of them critical, but one major aspect concerning the user is to understand that there is no average user therefore no product should be designed for a generic customer or audience. With a specific target audience a product can be targeted distinctly and it would automatically reflect on how well the positioning is. This might seem more of a marketing concept but the fact is that the distinction between marketing and usability engineering has become blurred over the years and both concepts often go hand in hand to help lead to success.

The fact is that in this digital age, marketing itself has evolved. There are factors that are turning brands into more than just brands, instead now brands are more like powerful assets while at the same time traditional marketing communication channels that have been responsible for growth of brand entity are now losing importance and customers are getting more control. This shows a relationship shift from brands and markets to brands and customers. The patterns have also shifted from researchers previously looking 
at company sales cycles now looking at customer buying cycles. An overall shift in the changing media consumption patterns and the selective attention of consumers has affected the overall buying patterns.

In the overall scheme of things usability can be defined as the extent to which specific users achieve specific goals with efficiency, effectiveness and subjective satisfaction in a specific context. There are two major types of usability: objective and subjective, which help differentiate between user performance and user experience. Where objective usability is about quantifying the user performance subjective usability refers to the perceived usability. The fact is that often user's overall appraisal of a product or an application or system is based on subjective usability. What a user feels about a product determines the perception that he creates in his mind about that particular product. We can talk about the mental model that is based on skills, behaviors and perceptions of an operator where perceptual processor, cognitive processor and motor processors work to retain, retrieve and store data in and from the brain but the point is that even though objective usability is an very critical factor for measuring usability, subjective usability is what creates the mental map for a user. It activates an image that creates the perception about that product.

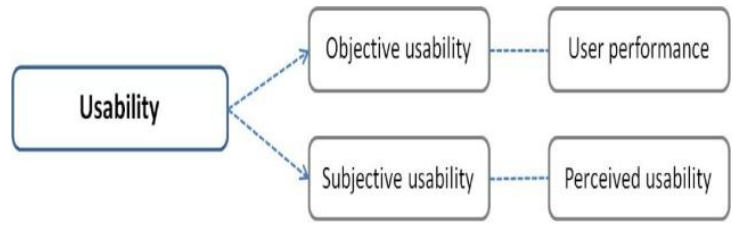

Figure 1: [11]

Perception is what perceived usability reflects and perceived usability is often what helps in user experience. User experience is the process, outcome and affect to the actions and responses involved in interactions between a user and a product. Where usability only covers certain components of user experience the rest of them are often catered to by the marketing side of the business. Therefore the connection is such that usability helps create the user experience and marketing helps project that user experience. For example when Apple launched iPhone in 2007, it was a game-changer in the world of mobile technology. Apple's technology was innovative and disruptive but it was so simple and unique that it captured a completely different target audience then those who were using products like Motorola, Nokia and Blackberry. Their technology was beyond the familiar and the ease of use and its quick learnability created such a perception with the users that till today iPhone is one of the leading mobile sellers. The reason for this success is not just the unprecedented technology but the user experience as well.

User experience not only focuses on the end-user and their needs and wants it basically sets quality goals that refer to the overall experience that a user goes through with a product, a system or an application. From the opening of a box of laptop to achieving the ultimate target of completing the user's work everything that the user goes through, be it frustration, joy, elation, excitement, depression, regret, it is all part of the user experience and this is what creates the perception regarding a product.

Today Companies and brands not only realize but they recognize the importance of usability, user experience and the relationship between these two elements and marketing. They understand that success is not just being able to give user what he asks for but giving it to him in a style that is a statement in itself and creates a long lasting relationship with the customer. What differentiates between a brand and an entity is that a brand is an individual target that a user can look for but an entity is much bigger than a brand, it is a persona, a presence that inculcates the brand with an identity all of its own. This is what the age of convergence has allowed companies to achieve, ultimately giving the consumers enough power to build or break brands. With everyone becoming a critic today a user is not just a silent spectator but a participant in the design phase as well, that is what participatory design is about.

The ultimate goal for going through all this process is to attain profitability through the products provided to the user. In a conceptual sense usability and marketing are two sides of the same coin but today the coins have flipped in such a way that they meet each other and meld together to form a platform that helps optimize performance by not only giving an innovative, branded customer experience but also ensuring quick and efficient delivery along with services that show a company's customer-centric approach.

\section{CONCLUSION}

As consumers face an increasing number of choices in the marketplace that is not even geographically restricted but dynamic enough to operate from anywhere at anytime providing so many options, user experience has become the differentiating factor. User experience is the key that unlocks the unique selling points that products can provide. To obtain this it is important to understand that bridging the gulf between usability and marketing is only possible through proper research and $R \& D$ are the future of the usability movement. In the next couple years the importance of research and development (R\&D) will increase tenfolds because with the increasing number of options providing something new and unique will be the biggest challenge.

In today's evolving world technology often plays the role of enabler that makes unique experiences possible. Fine dining has become an art now, the maître d' acknowledge regular customers, know the tables they like, the menu options they prefer and generally establish a relationship. This is being enabled by technology. When it comes to creating branded experience usability, marketing, operations and HR all play an important role but all of these elements go hand in hand with research. When research becomes a part of this framework an overall "design thinking" environment is created which understands and expects the customers needs and requirements, helping reshape the way businesses work. This enables businesses to remain true to their core values and achieve dynamic workplaces to integrate aesthetics, service experiences and positive emotions engagement to satisfy customers and foster loyal relationships that provide users with memorable and meaningful associations.

\section{REFERENCES}

[1] Nielsen. J. Usability Engineering. AP Professional. 1993.

[2] (IS0 DIS 9241-11).

[3] Jordan, P. W. (1998). Human factors for pleasure in product use. Applied ergonomics, 29(1), 25

[4] Tzou, R. C., \& Lu, H. P. (2009). Exploring the emotional, aesthetic, and ergonomic facets of innovative product on fashion technology acceptance model. Behavior \& Information Technology, 28(4), 311-322. 
[5] Crilly, N., Moultrie, J., \& Clarkson, P. J. (2004). Seeing things: consumer response to the visual domain in product design. Design studies, 25(6), 547-577.

[6] Lavie, T., \& Tractinsky, N. (2004). Assessing dimensions of perceived visual aesthetics of web sites. International journal of human-computer studies, 60(3), 269-298.

[7] Sonderegger, A., Sauer, J., \& Eichenberger, J. (2014). Expressive and classical aesthetics: two distinct concepts with highly similar effect patterns in user-artefact interaction. Behaviour \& Information Technology, 33(11), 1180-1191.

[8] Sonderegger, A., \& Sauer, J. (2010). The influence of design aesthetics in usability testing: Effects on user performance and perceived usability. Applied ergonomics, 41(3), 403-410.

[9] Ngo, D. C. L., Teo, L. S., \& Byrne, J. G. (2003). Modelling interface aesthetics. Information Sciences, $152,25-46$

[10] Blaszczyk, R. L. (2005). The Substance of Style: How the Rise of Aesthetic Value is Remaking Commerce, Culture, and Consciousness (review).Technology and Culture, 46(1), 261-262.
[11] Kokini, C. M., Lee, S., Koubek, R. J., \& Moon, S. K. (2012). Considering context: The role of mental workload and operator control in users' perceptions of usability. International Journal of Human-Computer Interaction, 28(9), 543-559.

[12] Hohmann, Luke. "Usability: Happier users mean greater profits." Information systems management 20.4 (2003): 66-76.

[13] Kellock, B. (1995). If it ain't broke... fix it anyway. Machinery and Production Engineering, 153(3900), 45-6

[14] Flowers, Jim. "Usability Engineering Can Change Our Thinking." Technology and Engineering Teacher 74.2 (2014): 18-22.

[15] Kokini, Christina M., et al. "Considering context: The role of mental workload and operator control in users' perceptions of usability." International Journal of Human-Computer Interaction 28.9 (2012): 543-559.

[16] Lockwood, Thomas. Design thinking: Integrating innovation, customer experience, and brand value. Skyhorse Publishing, Inc., 2010. 